\title{
Primary Effusion Lymphoma: Cytopathologic Diagnosis Using In Situ Molecular Genetic Analysis for Human Herpesvirus 8
}

Paul E. Wakely Jr, M.D., Geetha Menezes, M.D., Gerard J. Nuovo, M.D.

Department of Pathology, The Ohio State University, Columbus, Ohio

Primary effusion lymphoma is a form of diffuse large B-cell lymphoma with neoplastic cells largely limited to proliferation within major body cavities. Human herpes virus- 8 is both integral to and required for an unequivocal diagnosis of primary effusion lymphoma. Prior methods for virus identification include DNA extraction with Southern blot analysis or in situ hybridization from paraffinembedded samples. Our aim is to examine the utility of human herpesvirus-8 identification performed directly on smears from effusion samples by reverse transcriptase in situ polymerase chain reaction in patients with primary effusion lymphoma. Smears and cell block of body cavity fluids from five patients with effusions (three pleural, one peritoneal, and one both pleural and peritoneal)-were examined microscopically by conventional Papanicolaou and Romanowsky (Diff-Quik) staining, and by reverse transcriptase in situ polymerase chain reaction for human herpesvirus-8 detection. In situ hybridization was performed also for Epstein-Barr virus (EBER-1, -2), T-cell receptor- $\beta$, and kappa $(\kappa)$ and lambda $(\lambda)$ mRNA in all cases. Five adults ranged from 40-81 years of age. Three adults were HIV positive, one was a renal transplant recipient, and the oldest patient (Case 3) had the unusual distinction of a normal immune status. Two of three HIV-seropositive patients had concurrent Kaposi sarcoma. All samples were cytologically similar with lymphocytes having large-cell, plasmablastic, and immunoblastic morphology. Malignant cells from effusions were as follows: human herpesvirus-8 positive (all five cases), exhibited $\kappa$ monoclonal light chain (five cases), Epstein-Barr virus positive (three

Copyright (C) 2002 by The United States and Canadian Academy of Pathology, Inc.

VOL. 15, NO. 9, P. 944, 2002 Printed in the U.S.A.

Date of acceptance: May 2, 2002.

Address reprint requests to: Paul E. Wakely, Jr., M.D., Department of Pathology, The Ohio State University, College of Medicine, 414 Doan Hall, 410 West 10th Avenue, Columbus, Ohio 43210; e-mail: wakely-2@medctr.osu.edu; fax: 614-293-7626.

DOI: 10.1097/01.MP.0000024287.19070.96 cases), and T-cell $\beta$-gene receptor positive (two cases). Diffuse large B-cell lymphoma was evident in one peritoneal nodule $(<10 \%$ human herpesvirus-8 positive cells in contrast to $>90 \%$ positive in effusions, all $\kappa$ positive). Six other tissue specimens (lung, bone marrow, spleen, lymph node) were human herpesvirus-8 negative, and showed no evidence of lymphoma. Reverse transcriptase in situ polymerase chain reaction demonstrated nearcomplete restriction of human herpesvirus-8-infected malignant lymphoid cells to those in body cavities. Definitive diagnosis of primary effusion lymphoma is possible directly from cytologic smears/cell block by combining cytologic morphology with reverse transcriptase in situ polymerase chain reaction detection of human herpesvirus-8.

KEY WORDS: Cytopathology, Human herpesvirus-8, Primary effusion lymphoma, Reverse transcriptase in situ polymerase chain reaction.

Mod Pathol 2002;15(9):944-950

Primary effusion lymphoma is recognized in the World Health Organization classification of hematolymphoid neoplasms as a distinct subtype of diffuse large B-cell lymphoma (1) in which neoplastic cells proliferate within the major body cavities (pleural, peritoneal, and pericardial), typically without the formation of a grossly visible mass (2-6). The majority of patients are homosexual men who have contracted acquired immune deficiency syndrome (AIDS) or have been seropositive for human immunodeficiency virus (HIV) for several years. Once primary effusion lymphoma develops, most patients are resistant to conventional chemotherapy and succumb to their disease within months $(4,6)$. Human herpes virus-8, a DNA virus also termed Kaposi sarcoma-associated herpesvirus, is integral to the pathologic definition of primary effusion lymphoma and appears to be uniquely associated with this form of lymphoma. Human herpesvirus-8 is associated also with other nonlymphomatous neoplastic and nonneoplastic condi- 
tions, including Kaposi sarcoma and multicentric Castleman's disease (6).

Human herpesvirus-8 detection in primary effusion lymphoma most commonly has been performed using DNA extraction, polymerase chain reaction amplification, and Southern blot analysis by agarose gel electrophoresis $(2-4,7)$. Rarely, direct in situ hybridization with probes to Kaposi sarcoma ORF72 and ORF73 $(8,9)$, or in situ polymerase chain reaction localization from paraffin-embedded tissue samples, have been used to demonstrate the virus (10). We report our experience with five primary effusion lymphoma patients in whom the novel reverse transcriptase in situ polymerase chain reaction method was used to detect human herpesvirus-8 directly from the cytologic smears and cell blocks rather than from tissue sections or an agarose gel.

\section{CASE HISTORIES}

\section{Case 1}

A 51-year-old man presented with progressive exertional dyspnea, nonproductive cough, weight loss over the past month, and low-grade fever. As part of his 7-year HIV-seropositive status, he suffered from Kaposi sarcoma of the right testis, skin, and retroperitoneum and had episodes of oral candidiasis and cellulitis. Physical examination and radiographic study revealed widespread cutaneous Kaposi sarcoma and a left pleural effusion. A diagnosis of primary effusion lymphoma was made after $2 \mathrm{~L}$ of serous fluid were drained from his left thoracic cavity. A lung biopsy was nondiagnostic.

He was discharged after 1 month of chemotherapy and antiretroviral therapy. He was readmitted 5 months later with respiratory distress and died shortly afterward. No autopsy was performed.

\section{Case 2}

A 76-year-old HIV-negative man presented with a newly diagnosed pleural effusion, right-sided chest pain and shortness of breath. Thoracentesis at an outside hospital 3 weeks earlier had noted atypical lymphocytes in his pleural fluid. He had received continuous immunosuppressive medication (Imuran) since his cadaveric renal transplant 10 years earlier. Radiologic examination (computed tomography [CT]) revealed right-sided pleural effusion, marked ascites, and mesenteric nodules. Cytologic examination of both pleural and peritoneal fluid revealed malignant lymphocytes, and a diagnosis of primary effusion lymphoma was made. Because of the abnormal CT scan, laparoscopy was performed and revealed bilateral studding of the peritoneum in upper and lower quadrants. A $1.5-\mathrm{cm}$-diameter peritoneal nodule was removed, and a tissue diagnosis of diffuse large B-cell lymphoma was made. He was scheduled to receive chemotherapy in another state after discharge and has been lost to follow-up.

\section{Case 3}

An 81-year-old woman presented with a left pleural effusion. She had been plagued with several ailments including adult-onset diabetes mellitus, atrial fibrillation, chronic obstructive pulmonary disease, and an unspecified rheumatologic dysfunction with Raynaud's phenomenon. Progressive weakness and profound hypoglycemia led to the current hospital admission. Extensive radiologic imaging performed after a diagnosis of primary effusion lymphoma was made from her pleural fluid showed no mass lesions elsewhere. A serologic test for HIV was negative. Progressive pulmonary deterioration led to her death after almost 3 months of hospitalization. No autopsy was performed.

\section{Case 4}

A 49-year-old man presented with nausea, vomiting, and acute abdominal pain. In addition to being HIV seropositive for the past 15 years, he had been diagnosed with Kaposi sarcoma and disseminated histoplasmosis 5 years earlier. Splenectomy 7 months before admission had revealed Castleman's disease and hypersplenism without evidence of Kaposi-sarcoma or lymphoma. Physical examination showed a distended abdomen, massive ascites, but no palpable mass. Two liters of serous fluid were removed from his peritoneum, and a diagnosis of primary effusion lymphoma was made. The patient returned to the hospital with recurrent ascites and a right pleural effusion after two cycles of chemotherapy. Malignant lymphocytes were found in his pleural fluid on this second admission. He died at home 2 months later. Autopsy found residual Kaposi sarcoma, but no evidence of solid lymphoma in any organ. Death was ascribed to sepsis.

\section{Case 5}

A 40-year-old man, hepatitis C positive and HIV seropositive for 9 years, presented to the emergency room with bilateral pleural effusions, shortness of breath, and diarrhea. He was receiving no medication other than antibiotics. His hospital course was remarkable for thoracentesis of a large left pleural effusion and institution of intrapleural chemotherapy after a diagnosis of primary effusion lymphoma was made. He left the hospital against medical advice and has been lost to follow-up.

\section{MATERIALS AND METHODS}

Peritoneal (Cases 2 and 4) and pleural (Cases 1-5) fluid collected from each patient was processed in a 
routine manner for cytologic examination by preparing cytocentrifugation smears and monolayer smears (Cytyc Corp., Boxborough, MA) stained with a modified Papanicolaou stain. Additionally, cytocentrifugation smears performed in Cases 1, 4, and 5 were stained with a Diff-Quik stain (Biochemical Sciences, Inc., Swedesboro, NJ). Cases 1 and 3 had a portion of the cytologic material prepared as a cell block. No conventional direct smears were made on any case. Tissue biopsies of lung, lymph node, bone marrow, peritoneal nodule, and spleen as well as cell blocks were processed in a routine manner for paraffin embedding and histologic analysis.

\section{Reverse Transcriptase In Situ Polymerase Chain Reaction}

A review of this methodology has recently been described (11). In brief, cell block and paraffinembedded tissue samples were digested with pep$\sin \left(2 \mathrm{mg} / \mathrm{mL}, 37^{\circ} \mathrm{C}\right)$ for 20 to 60 minutes. For alcohol-fixed effusion smears, protease digestion was accomplished with proteinase $\mathrm{K}(50 \mu \mathrm{g} / \mathrm{mL}$, room temperature) rather than pepsin for $10 \mathrm{~min}-$ utes. All specimens were then treated overnight with RNase-free DNase solution made according to the manufacturer's recommendations (10 units per tissue section, $37^{\circ} \mathrm{C}$, Boehringer Mannheim, Indianapolis, IN). The EZ reverse transcriptase polymerase chain reaction system (Perkin Elmer, Nôrwalk, CT) was employed. Reverse transcriptase/ amplifying solution contained the EZ rTh buffer, $200 \mu \mathrm{M}$ each of dNTP, $10 \mu \mathrm{m}$ of digoxigenin dUTP, $400 \mu \mathrm{g} / \mathrm{mL}$ of bovine serum albumin, $40 \mathrm{U}$ of $\mathrm{RNa}$ sin, $20 \mu \mathrm{M}$ of the appropriate 5 ' and 3' primer pairs, $2.5 \mathrm{~mm}$ of $\mathrm{MnCl}_{2}$, and $5 \mathrm{U}$ of rTth.

For human herpesvirus-8 analysis, primers corresponding to the T0.7 human herpesvirus- 8 mRNA expressed in latent infection were used (Sigma Genosys, The Woodlands, TX; 7). For T-cell receptor- $\beta$ mRNA expression, primers corresponding to each of the 25 different VH segments were employed as previously described (12). After an initial incubation of $65^{\circ} \mathrm{C}$ for 30 minutes and a denaturation of $94^{\circ} \mathrm{C}$ for 3 minutes, 20 cycles were performed at $60^{\circ}$ $\mathrm{C}$ for 1 minute and $94^{\circ} \mathrm{C}$ for 30 seconds. The digoxigenin-labeled cDNA product was detected as a dark blue signal generated via the action of the alkaline phosphatase-antidigoxigenin conjugate (30 $\min$ at $37^{\circ} \mathrm{C}$ ) on the chromogens nitroblue tetrazolium and 5-bromo-4-chloro-3-iondolyl phosphate. A nuclear fast red counterstain was then applied.

An important aspect of the reverse transcriptase in situ polymerase chain reaction protocol is that the negative and positive controls must be performed on the same glass slide with the test case to demonstrate loss of nonspecific DNA synthesis. A human herpesvirus-8 signal was considered posi- tive when it turned dark blue and localized to the cell nucleus. The positive control is one in which no DNase digestion is applied; this should yield an intense nuclear signal in all cell types that demonstrates optimal protease digestion for that specific cell preparation. A weak signal either denotes inadequate protease digestion or, if associated with poor morphology, overdigestion with the protease. The negative control is also an in situ polymerase chain reaction in which the cells are treated with DNase, but primers are employed that do not correspond to any target within the cell. In this study, human papillomavirus-specific primers (which cannot infect lymphocytes) were employed. These negative control cells stain pink only with the nuclear fast red. The absence of a signal demonstrates that genomic DNA-based synthesis is not occurring. Controls for human herpesvirus-8 RNA consisted of two cases of Kaposi sarcoma (positive control), and two cases of seborrheic keratosis (negative control). An additional control used on cell block specimens only was pretreatment in RNase before reverse transcriptase for human herpesvirus-8, as described previously (12).

\section{In Situ Hybridization}

Epstein-Barr virus (using probes for EBER-1, and EBER-2) as well as $\kappa$ and $\lambda$ mRNA were detected by standard in situ hybridization using the Ventana Corp. (Tucson, AZ) automated Benchmark system according to the manufacturer's recommendations.

\section{Cytogenetics}

Conventional karyotyping was performed on cells from body cavity (peritoneal) fluid in one case (Case 4).

\section{RESULTS}

Cytologic specimens contained only lymphocytes, and all cases showed similar cytopathologic features. Cells were dispersed primarily in a singlecell (dissociated) arrangement, although some flat loosely clustered aggregates were present. Lymphocytes were large (approximately 2-2.5× diameter of adjacent red cells) with markedly increased nuclear and cytoplasmic ratios, and a moderate amount of finely granular amphophilic or basophilic cytoplasm with discrete cell borders. Whenever a zone of perinuclear cytoplasmic paleness gave way to peripheral basophilia (seen only in Diff-Quik stained smears), this imparted an immunoblastic and plasmablastic appearance to such cells. (Fig. 1) Cytoplasmic vacuoles were largely absent and when present, were small and indistinct. Most cells harbored a single nucleus, but a minority were 

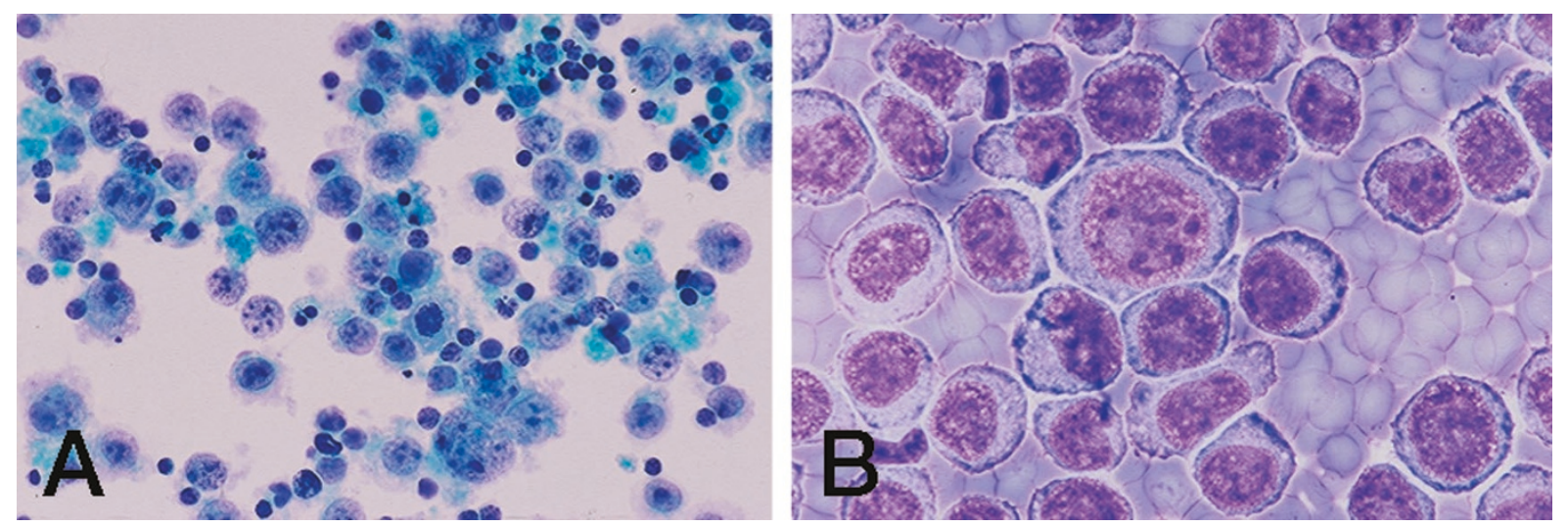

FIGURE 1. A, low-power view of a liquid-based (monolayer) preparation shows a predominance of large lymphocytes exhibiting rounded nuclei, coarsely granular chromatin, and a moderate amount of cytoplasm. Many of the smudged small nuclei represent pyknosis (individual cell necrosis), not small lymphocytes. Papanicolaou stain. B, a monomorphic population of large cells shows anisonucleosis, rounded nuclei, chromatin coarseness, and abundant cytoplasm. The centrally pale cytoplasm merges with a peripheral zone of intense basophilia in many cells producing a plasmablastic look. Diff-Quik stain.

binucleated with mirror-image Reed-Sternberg like nuclei; even fewer cells had three to four nuclei per cell. (Fig. 2) Nuclei were primarily rounded but also displayed irregular contours that varied from slight to exaggerated; some were multilobated. Nuclear chromatin was coarsely reticulated. Many cells had one or more misshapen, variably enlarged nucleoli that were accentuated in Papanicolaou-stained smears. Mitotic figures were obvious and plentiful in all cases, and the slide background had abundant individual cell necrosis in only one case. Lymphoglandular bodies were visible in Diff-Quik stained smears only. No cells exhibited the typical cytomorphology of Burkitt lymphoma, thăt is, mèdiumsized isomorphic cells with meager amounts of coarsely vacuolated basophilic cytoplasm, and little if any evidence of nuclear pleomorphism.

Table 1 summarizes the pertinent clinical and laboratory values for each patient. This cohort consisted of four men and one woman ranging from 40 to 81 years of age $(x=59 \mathrm{y})$. Three patients were immunocompromised by HIV infection for a prolonged period (7-15 y), one was immune suppressed from a longstanding renal allograft (10 y), and the fifth patient had no known immune deficiency. Three patients died of their disease within months of their primary effusion lymphoma diagnosis, whereas two patients have been lost to follow-up. Two of three HIV-positive patients also manifested Kaposi sarcoma. Bone marrow biopsy was performed in four patients; it showed nonspecific plasma cell hyperplasia in two patients, and no pathologic abnormality in two other patients.

Malignant lymphocytes were human herpesvirus-8 positive by reverse transcriptase in situ polymerase chain reaction in all effusion samples. Human herpesvirus-8-positive lymphocytes had a discrete darkblue nuclear signal. In some, it was smudged and homogeneous, whereas in others the nucleus exhibited coarse granular staining suggesting viral infection (Fig. 3). All effusions showed B-cell immunoglobulin (Ig) gene rearrangement by in situ hybridization with

\section{Prohibited}
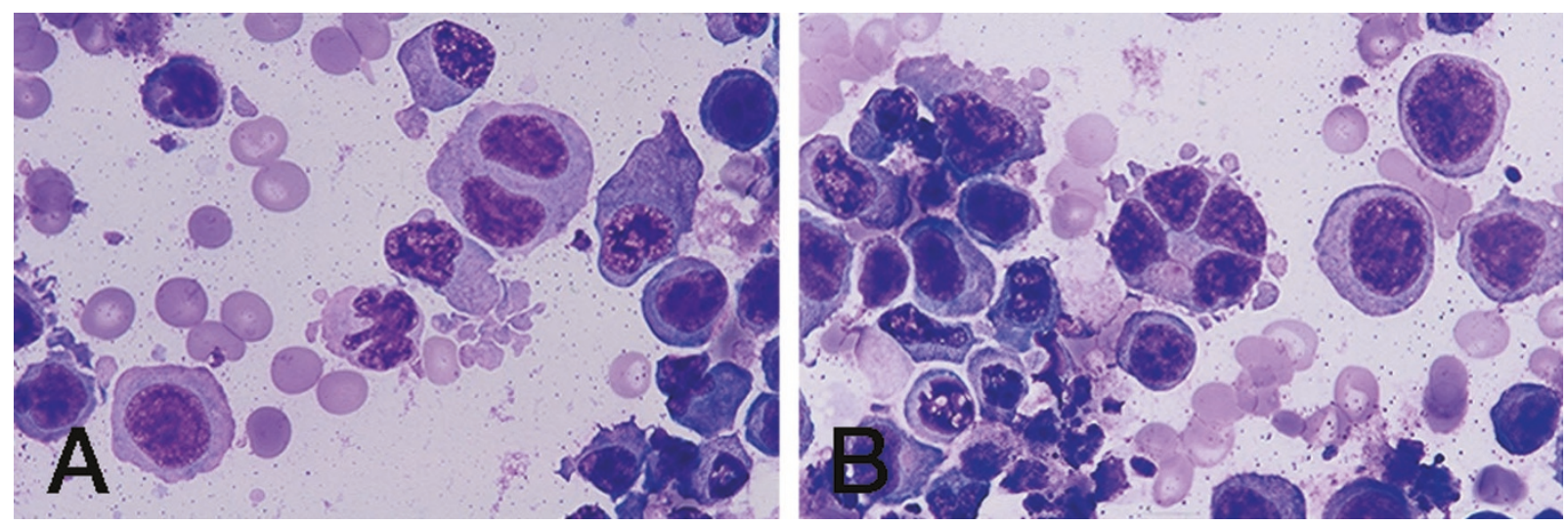

FIGURE 2. A, greater lymphocyte heterogeneity exists in this field with a combination of single-nucleated large cells having voluminous amphophilic cytoplasm, a large mirror image binucleated cell, and a cell with a markedly contorted nuclear outline. B, a four-lobed nucleus is surrounded by more conventional mononuclear large cells. Note the small globular lymphoglandular bodies that partially surround this multilobated cell. Diff-Quik stain. 


\begin{tabular}{|c|c|c|c|c|c|}
\hline Variable & Case 1 & Case 2 & Case 3 & Case 4 & Case 5 \\
\hline Age $(y) / \operatorname{sex}$ & $51 / \mathrm{M}$ & $76 / \mathrm{M}$ & $81 / \mathrm{F}$ & $49 / \mathrm{M}$ & $40 / \mathrm{M}$ \\
\hline Clinical outcome & DOD & No F-U & DOD & DOD & No F-U \\
\hline Specimen type & Pleural & Pleural \& peritoneal & Pleural & Pleural \& peritoneal & Pleural \\
\hline HIV status & Positive for $7 \mathrm{y}$ & Negative & Negative & Positive for $15 \mathrm{y}$ & Positive for $9 \mathrm{y}$ \\
\hline Kaposi sarcoma & Present & Absent & Absent & Present & Absent \\
\hline Organ Tx & None & Renal & None & None & None \\
\hline Bone marrow biopsy & $\begin{array}{l}\text { Plasma cell } \\
\text { hyperplasia }\end{array}$ & $\begin{array}{l}\text { No pathologic } \\
\text { change }\end{array}$ & $\begin{array}{l}\text { No pathologic } \\
\text { change }\end{array}$ & $\begin{array}{l}\text { Lymphocyte and } \\
\text { plasma cell } \\
\text { hyperplasia }\end{array}$ & Not done \\
\hline FCM & No sIg & Monoclonal $\kappa$ & Monoclonal $\kappa$ & No sIg & No sIg \\
\hline Light-chain ISH & Monoclonal $\lambda$ & Monoclonal $\kappa$ & Monoclonal $\kappa$ & Monoclonal $\kappa$ & Monoclonal $\kappa$ \\
\hline HHV-8, effusions (RTIS PCR) & Positive (>90\%) & Positive (>90\%) & Positive $(>90 \%)$ & Positive (>90\%) & Positive $(>90 \%)$ \\
\hline $\begin{array}{l}\text { HHV-8, peritoneal lymphoma } \\
\text { (RTIS PCR) }\end{array}$ & N/A & Positive $(<10 \%)$ & N/A & N/A & N/A \\
\hline HHV-8, bone marrow (RTIS PCR) & Negative & Negative & N/A & $\mathrm{N} / \mathrm{A}$ & $\mathrm{N} / \mathrm{A}$ \\
\hline EBV, effusions & Positive (10\%) & Negative & Negative & Positive (1\%) & Positive $(>90 \%)$ \\
\hline TCR-beta & Positive & Negative & Negative & Positive & Negative \\
\hline
\end{tabular}

DOD, dead of disease; F-U, follow-up; HIV, human immunodeficiency virus; Tx, transplantation; RTIS PCR, reverse transcriptase in situ polymerase chain reaction; HHV, human herpesvirus; EBV, Epstein-Barr virus; FCM, flow cytometry; TCR, T-cell receptor.
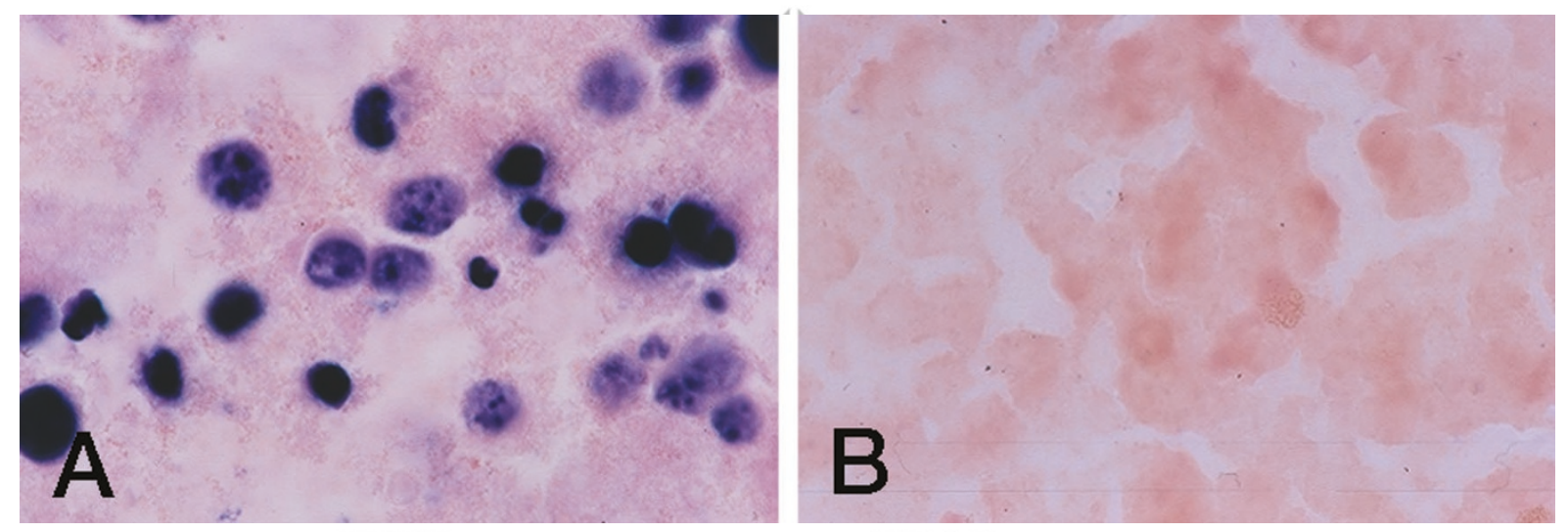

FIGURE 3. A, human herpesvirus-8 positive signal shows staining restricted to the nucleus. In some nuclei the signal has a densely homogeneous smudged appearance, whereas in others it is coarsely granular. Nitroblue tetrazolium/-bromo-4-chloro-3-iondolyl phosphate stain, nuclear fast red counterstain. B, negative control in which primers for HPV were substituted for human herpesvirus-8 shows cells that lack any signal. One can barely discern the shadowy cell outlines. Nuclear fast red stain.

four cases having $\kappa$, and one, $\lambda$ light chain restriction. By flow cytometry, two cases demonstrated ' $\kappa$ lightchain monoclonality. However, immunophenotyping was indeterminate (null-cell phenotype) in three patients because of the lack of sIg expression and panB-cell markers (CD19/CD20). Two patients also had $\mathrm{T}$-cell gene rearrangement of the lymphoma cells with positive signal for a monoclonal T-cell receptor $\beta$-chain pattern. Epstein-Barr virus positivity occurred in 90,10 , and $1 \%$ of lymphoma cells in three of five patients.

Histologic sections of the peritoneal implant (Case 2) showed replacement of tissue by a diffuse monomorphous large-cell infiltrate intersected by thin collagen bands. Touch imprint of the nodule showed cells morphologically identical to those in the effusion sample. Extremely few tumor cells in this tissue were positive for human herpesvirus-8 by reverse transcriptase in situ polymerase chain reaction $(<10 \%$ of cells), and tumor cells showed $\kappa$ light-chain restriction by in situ hybridization. A diagnosis of extracavitary primary effusion lymphoma (diffuse large B-cell lymphoma) was made. An axillary lymph node in another patient (Case 4) showed histologic features of the late stage of HIVassociated lymphadenopathy with lymphocyte depletion, and regressive germinal centers but was human herpesvirus-8 negative. Additionally, tissue examination of the spleen (Case 4), bone marrow (Cases 1, 2, 4), and lung (Case 1) were human herpesvirus-8 negative. Conventional cytogenetic analysis of lymphoma cells from peritoneal fluid of Case 4 showed hyperdiploidy with additional chromosomes 3, 7, and 8.

\section{DISCUSSION}

Primary effusion lymphoma is a rare, primarily liquid-phase lymphoma that is estimated to account for approximately 3\% of AIDS-related lymphomas, and $<1 \%$ of all non-AIDS-related large cell 
lymphomas (6). Primary effusion lymphoma was first acknowledged as a distinct entity in 1995 when a consistent association with infection by human herpesvirus-8 was documented (2), although reports of AIDS-related lymphomas consistent with primary effusion lymphoma had been recognized several years earlier. Since then, numerous studies have confirmed the distinct clinicopathologic, epidemiologic, virologic, and molecular features of primary effusion lymphoma (3-5).

The relatively unique features of primary effusion lymphoma include the following: a liquid rather than a solid proliferation of malignant lymphocytes usually confined to growth within the major body cavities; a large-cell, immunoblastic, plasmablastic, or anaplastic cytomorphology; a B-cell lymphoma that often has an indeterminate immunophenotype by nonmolecular methods; a tumor that primarily, but not exclusively develops in immune-suppressed individuals (particularly HIV-positive homosexual males); and the universal presence of human herpesvirus-8. Our Case 3 complies with those rare accounts of primary effusion lymphoma in HIV-seronegative patients with no prior history of transplantation, but who are represented by an advanced age. Primary effusion lymphoma in these non-HIV patients tends to occur at least 2-3 decades later than it does in HIV-positive patients (6). This series further documents the expanded clinical spectrum of primary effusion lymphoma, with three patients fitting the typical clinical scenario of longstanding HIV-positivity, one patient having transplantation-induced immunosuppression, and one elderly patient having ho documented immunodeficiency.

Although primary effusion lymphoma remains restricted to the body cavity of origin in most instances, more than one cavity may be involved (our Cases 2 and 4). Because the prognosis is so poor for all patients, this spread into multiple cavities appears to have no prognostic import. Infiltration into lymphatics or subserosal tissue may cause the formation of mass lesions as it did in our Case 2; however, expansion into extracavitary sites with the production of a solid tissue mass remains a rare event $(10,13-16)$.

The cytomorphology of our cases conforms to what has previously been described in primary effusion lymphoma $(1-3,5)$. Monolayer smears were composed principally of large mononuclear cells having immunoblastic/plasmablastic features with enlarged nuclei, one or more macronucleoli, and an abundant amphophilic to basophilic cytoplasm. Enlarged nuclei had both smooth and irregular contours. Extreme indentations of the nucleus in a small subset of cells created multilobated fleurettelike structures. Occasional cells were binucleated with one or more macronucleoli imitating ReedSternberg cells. A cellular diathesis was seen in one case. No viral inclusions were identified in any of our cases by light microscopy. Interestingly, it is extremely rare to identify light-microscopic viral inclusions within lymphoma cells (9), yet electron microscopy has definitively demonstrated the presence of virus within these cells (10).

Primary effusion lymphoma is most often genotypically a B-cell lymphoma with all patients having clonal Ig heavy chain gene rearrangements (3). It is thought to represent an advanced-stage (preplasmacytic) of B-cell differentiation (6). Nonetheless, primary effusion lymphoma typically lacks any immunophenotypic evidence of B- or T-cell differentiation by conventional immunohistochemistry or flow cytometry. Surface marker analysis characteristically fails to reveal surface Ig, or pan B-cell markers (CD19, CD20), as occurred in 3 of our 5 cases. Cells are CD45 positive, however, and activationassociated antigens CD30, CD38, CD71, and EMA may be expressed (5). By using a highly sensitive test such as the amplified in situ assay we were able to detect light-chain expression and restriction in each of our cases. Primary effusion lymphoma also has been proven to exhibit genotypic infidelity with rare cases having bigenotypic or biphenotypic Band T-cell expression $(9,14,17,18)$. Two of our patients (Cases 1,4) exhibited a bigenotypic nature by having both B- and T-cell gene rearrangements in lymphoma cells. To our knowledge, this represents the first in situ documentation of gene rearrangement in primary effusion lymphoma.

Over $80 \%$ of primary effusion lymphoma cases are Epstein-Barr virus infected. This is particularly so for those primary effusion lymphoma patients that are HIV positive, whereas HIV-negative patients are usually Epstein-Barr virus negative. Epstein-Barr virus-positive cells were present in three of five cases, but in only one case in this series were most of the tumor cells infected by EpsteinBarr virus. This incomplete presence of EpsteinBarr virus in primary effusion lymphoma is consistent with prior reports surmising that Epstein-Barr virus probably plays a secondary role in the pathogenesis of primary effusion lymphoma because it is not indispensable to its development (3).

The sine qua non of primary effusion lymphoma that distinguishes it from all other lymphomas is the presence of human herpesvirus- 8 within the tumor (19). From a purely morphological standpoint, the major differential diagnoses of primary effusion lymphoma are pyothorax-associated lymphoma, Burkitt lymphoma, lymphomatous effusion as a result of contiguous or disseminated lymphoma, malignant melanoma, and pleomorphic non-small cell carcinoma. The latter two nonlymphoid neoplasms are readily excluded by conventional immunophenotyping. Regarding the lymphomas, pyothorax-associated lymphoma occurs typically in the pleural cavity after a multiyear his- 
tory of pyothorax and grows as a solid mass. Burkitt lymphoma may present clinically as a lymphomatous effusion (particularly in the setting of AIDS), but the cytomorphology is that of lymphoblasts, not a large cell or immunoblastic or anaplastic lymphoma. Absence of human herpesvirus-8 infection in each of these lymphomas readily eliminates them from consideration, thus confirming the critical importance of a reliable and accessible test for human herpesvirus-8. The lack of human herpesvirus- 8 in bone marrow, lung, spleen, and lymph node in our series reaffirms prior reports that human herpesvirus- 8 has a definite predilection for cells within body cavities and rarely affects cells outside this site.

Identification of human herpesvirus-8 is generally accomplished by DNA extraction from cells in suspension or from tissue samples, amplified, and analyzed on a gel (polymerase chain reaction and/or Southern blot). Others have used direct in situ polymerase chain reaction to identify the virus (9). The advantage of reverse transcriptase in situ polymerase chain reaction include its higher sensitivity, and the use of nonradioactive long-lived inexpensive oligomers. It is the only amplification technique that allows target-specific incorporation of the reporter nucleotide into the DNA molecule during polymerase chain reaction amplification. The reverse transcriptase in situ polymerase chain reaction method used in this series allows for detection of the viral signal on smears rather than on a gel. With this methodology, cell morphology is preserved thus allowing the pathologist to directly correlate the nuclear viral signal with cytopathology.

In summary, detection of human herpesvirus-8 is possible with direct cell localization in cytologic specimens using reverse transcriptase in situ polymerase chain reaction. Detection of human herpesvirus- 8 using this methodology coupled with appropriate cytologic morphology is diagnostic of primary effusion lymphoma.

Acknowledgment: The authors wish to thank Drs. Alvin M. Schmidt and Robert R. Rickert, St. Barnabas Hospital, Livingston, NJ, for providing a clinical history and glass slides, respectively, on Case 3 and to thank Dr. J.K.C. Chan for reviewing the tissue sections in Case 2.

\section{REFERENCES}

1. Jaffe ES, Harris NL, Stein H, Vardiman JW, editors. World Health Organization classification of tumours. Pathology and genetics of tumour of haematopoietic and lymphoid tissues. Lyon, France: IARC Press; 2001.

2. Cesarman E, Chang Y, Moore PS, Said JW, Knowles DM. Kaposi's sarcoma-associated herpesvirus-like DNA se- quences are present in AIDS-related body cavity-based lymphomas. N Engl J Med 1995;332:1186-91.

3. Nador RG, Cesarman E, Chadburn A, Dawson DB, Ansari MQ, Said J, et al. Primary effusion lymphoma: a distinct clinicopathologic entity associated with the Kaposi's sarcoma-associated herpesvirus. Blood 1996;88:645-56.

4. Carbone A, Blochii A, Vacher E, Agonal V, Pasture C, Dalla Palma P, et al. Kaposi's sarcoma-associated herpesvirus DNA sequences in AIDS-related and AIDS-unrelated lymphomatous effusion. Br J Haematol 1996;94:533-43.

5. Anseris MQ, Dawson DB, Nadir R, Rutherford C, Schneider NR, Latimer MJ, et al. Primary body cavity-based AIDSrelated lymphomas. Am J Clin Pathol 1996;105:221-9.

6. Knowles DM, Chadburn A. Lymphadenopathy and the lymphoid neoplasms associated with the acquired immune deficiency syndrome. In: Knowles DM, editor. Neoplastic hematopathology. 2nd ed. Philadelphia, PA: Lippincott; 2001. p. $1043-8$.

7. Chang Y, Cesarman E, Pessin MS, Lee F, Culpepper J, Knowles DM, et al. Identification of herpes-virus-like DNA sequences in AIDS-associated Kaposi's sarcoma. Science 1994;266:1865-9.

8. Said JW, Rettig MR, Heppner K, Vescio RA, Schiller G, Ma HJ, et al. Localization of Kaposi's sarcoma-associated herpesvirus in bone marrow biopsy samples from patients with multiple myeloma. Blood 1997;11:4278-82.

9. Said JW, Shintaku IP, Asou H, deVos S, Baker J, Hanson G, et al. Herpesvirus 8 inclusions in primary effusion lymphoma: report of a unique case with T-cell phenotype. Arch Pathol Lab Med 1999;123:257-60.

10. Hsi ED, Foreman KE, Duggan J, Alkan S, Kauffman CA, Aronow HD, et al. Molecular and pathologic characterization of an AIDS-related body cavity-based lymphoma, including ultrastructural demonstration of human herpesvirus-8. A case report. Am J Surg Pathol 1998;22:493-9.

11. Nuovo GJ. Co-labeling using in situ PCR: a review. J Histochem Cytochem 2001;49:1329-39.

12. Nuovo MA, Nuovo GJ. Utility of HHV8 RNA detection for differentiating Kaposi's sarcoma from its mimics. J Cutan Pathol 2001;28:248-55.

13. DePond W, Said JW, Tasaka T, de Vos S, Kahn D, Cesarman E, et al. Kaposi's sarcoma-associated herpesvirus and human herpesvirus 8(KSHV/HHV8)-associated lymphoma of the bowel. Report of two cases in HIV-positive men with secondary effusion lymphomas. Am J Surg Pathol 1997;21:719-24.

14. Hollingsworth HC, Stetler-Stevenson M, Gagneten D, Kingma DW, Raffeld M, Jaffe ES. Immunodeficiencyassociated malignant lymphoma: three cases showing genotypic evidence of both T-and B-cell lineages. Am J Surg Pathol 1994;18:1092-101.

15. Katano H, Suda T, Morishita Y, Yamamoto K, Hoshino Y, Nakamura K, et al. Human herpesvirus 8-associated solid lymphomas that occur in AIDS patients take anaplastic large cell morphology. Mod Pathol 2000;13:77-85.

16. Chadburn A, Cesarman E, Hyjek E, Liu Y-F, Mulligan L, Said J, et al. Mod Pathol 2002;15:234-5A.

17. Otsuki T, Kumar S, Ensoli B, Kingma DW, Yano T, StetlerStevenson M, et al. Detection of HHV-8/KSHV DNA sequences in AIDS-associated extranodal lymphoid malignancies. Leukemia 1996;10:1358-62.

18. Said JW, Tasaka T, Takeuchi S, Asou H, deVos S, Cesarman E, et al. Primary effusion lymphoma in women: report of two cases of Kaposi's sarcoma herpes virus-associated effusionbased lymphoma in human immunodeficiency virusnegative women. Blood 1996;88:3124-8.

19. Gaidano G, Carbone A. Primary effusion lymphoma: a liquid phase lymphoma of fluid-filled body cavities. Adv Cancer Res 2001;80:115-46. 